\title{
Identidade cultural em discursos de terreiro
}

Jonatas ELIAKIM

\section{Considerações iniciais}

A história cultural brasileira pode ser aprendida e apreendida não apenas em livros de História, mas também em terreiros de umbanda. A umbanda reinterpreta os valores, as visões históricas e os acontecimentos nacionais, dialogando com a realidade. As classes de pertencimento de seus espíritos refletem também grupos que geralmente sofrem ou sofreram exclusão social, uma marca de resistência e preservação de um modo de dialogar com as memórias da realidade social de forma a articular, pelos rituais, a inclusão social. Portadoras de vozes ancestrais inconscientes, essas memórias, uma vez resgatadas, podem distribuir benefícios psíquicos e simbólicos aos seus herdeiros. As personagens que compõem as divindades e espíritos na umbanda assinalam a necessidade de 
atenção e inclusão da comunidade de fiéis do passado (memória coletiva) e do presente.

A particularidade religiosa da umbanda, que não é nem africana nem cristã, pode ser a expressão de um patrimônio cultural pujante e digno da realidade social brasileira. Ela comporta processos de inclusão social e pode ser um meio de elaboração de experiências sociais traumáticas para significativos grupos sociais brasileiros. O estudo do imaginário popular religioso da umbanda, além de permitir a obtenção de subsídios para o conhecimento da realidade social e psíquica brasileira, pode ajudar o desenvolvimento de estratégias éticas para o trabalho com comunidades e a consolidação de um método empírico de estudo da alteridade.

A umbanda é ainda uma oportunidade excelente para refletir formas sociais e alternativas de resistência étnica e cultural. Ela oferece uma oportunidade ímpar para aprender com os setores populares a relativizar o psicologismo e o individualismo, consagra o humano, pondo no seu panteão a totalidade de suas sutilezas, agradáveis ou não, um testemunho de uma ética singular, de vocação universal, que propõe um sentido de inclusão psicológica e social, politicamente indócil a tentativas históricas e teóricas de manipulação.

Por todas essas características, a umbanda é um lugar de excelência para abrigar as minorias despossuídas, em especial os negros, ainda que, como observa Pierucci (2004, online), "afirmativamente afro e marcantemente popular, ela não se fechava etnicamente em sua negritude, mas se oferecia brasileiramente a todos os brasileiros", ou seja, esse lugar em que encontramos o imaginário do negro no Brasil é também, por não se fechar para o resto dos grupos sociais do país, um espaço de diálogo, de amálgama de grupos socioculturais, como é o próprio brasileiro. 
A umbanda trabalha em registros engajados socialmente. A justiça, vista pela ótica dos subalternos, dos despossuídos, marginalizados ou precariamente dispostos nos lugares sociais, aparece como um fundamento moral da prática mágica umbandista, observa Negrão (1996). Os espaços de rituais de umbanda recebem, regularmente, fiéis paramentados e preparados para louvar valores ditos universais. Eles se apresentam com trajes de universos de sentidos variados. A depender do dia de rito, chamado de "gira", pode-se ver penas, cocares e flechas; em outro momento, chapéus de couro, celas, chicotes etc. Este cenário modular, fluido, apesar de gozar de pouco prestígio na sociedade brasileira, ainda é composto por uma grande quantidade de seguidores que também é parte ativa da situação. Música, gritos, chamamentos e incentivos vêm dos fiéis (assistência) que, mais que contemplativos, têm papel fundamental no transcorrer da cena ritualística.

Nos rituais em que se dão uma gira de umbanda, as entidades que os médiuns espiritualistas incorporam são personagens em posição intermediária entre os homens e os deuses, símbolos de superioridade e de virtudes valorizadas por determinado grupo, como força, inteligência, velocidade. Cabe à assistência e ao atabaqueiro, invocar aqueles que serão responsáveis pela conexão entre o universo do divino e do mundano. Eles também devem manter o canto incentivador durante todo o ritual, que contribui para que a energia continue fluindo durante a ocasião. E ainda são eles que detêm as demandas, que exigem uma atuação performática eficaz, que buscam melhoria para a própria vida, ou apenas um momento de paz, de prazer, de conforto, de acolhimento.

Tendo em vista que os todos os discursos se concretizam por meio de gêneros, propomos, como objetivo, identificar, no gênero de discurso ponto de umbanda, os modos de organização e de inscrição dos sujeitos na cenografia e verificar a relação entre eles e a 
identidade cultural. $O$ aprofundamento da concepção de gênero de discurso contribui na compreensão dos efeitos de sentido decorrentes dessas práticas sociais.

Debruçamos sobre as questões que envolvem os discursos do ponto de umbanda para entender algumas das identidades que compõem a sociedade brasileira e os mecanismos que constroem, pelo discurso, os valores que ela defende. Embora cada um desses discursos possua características próprias, eles são usados, de igual modo, para invocar e reafirmar o valor social ou conferir poder, encorajar e apresentar uma entidade espiritual que representa uma identidade sociocultural.

Para nosso estudo, tomamos como referencial teórico-metodológico a Análise do Discurso de linha francesa, em especial, a praticada por Dominique Maingueneau (2000, 2001, 2008a, 2008b, $2009,2010,2015)$, pois ela é a ferramenta ideal para identificar, nesse espaço discursivo, o vínculo entre os enunciadores e seus co-enunciadores, parceiros da comunicação verbal.

$\mathrm{Na}$ medida em que o corpus selecionado, composto por sete pontos de invocação usados em rituais de umbanda, implica uma situação de comunicação, pela abordagem de gênero de discurso, mostramos, no funcionamento discursivo, os valores, as convicções, as crenças e os conflitos da sociedade, que podem ser entendidos a partir da consideração dos lugares sociais e de suas implicações com a rede de lugares discursivos em que os falantes se inscrevem para enunciar. 


\section{A Análise do Discurso}

A Análise do Discurso (AD) é constituída como campo autônomo que faz interface com outras áreas do conhecimento, cujo objeto é o discurso, desse modo, é interdisciplinar. A AD nasce numa nova configuração social e, por ser interdisciplinar, ela também é usada como ferramenta em outras disciplinas com a intenção de resolver problemas sociais. Na sociedade atual, a noção de texto mudou e, com ela, a ideia de discurso, de modo que hoje se compreende que os elementos semióticos componentes de um texto contribuem para construir seus efeitos de sentido.

Vale ressaltar que a $\mathrm{AD}$ é uma disciplina da Linguística e da Comunicação, com um pesquisador que se preocupa com os efeitos de sentido produzidos na interação dos sujeitos. "O analista do discurso refletirá sobre o dispositivo de comunicação, a articulação entre o espaço público e maneira como o texto é organizado" (MAINGUENEAU, 2000, p. 3), além das condições sócio-históricas de produção, recepção e circulação.

A linha seguida nesta pesquisa é a francesa: voltada para a orientação linguística, com ênfase no marxismo e na psicanálise. Para ela, os sujeitos são condicionados por uma formação discursiva (FD), com privilégio para o contato com a história, com textos de arquivos, que emanam das instituições. Ela concebe o discurso como instrumento de comunicação a serviço dos sujeitos específicos, movido por propósitos específicos, sempre contextualizado, produzido por um sujeito, e interativo. O discurso é uma ação sobre o outro, uma prática social interativa que necessita de um sujeito que assuma, por meio dele, determinada posição em determinado contexto sócio-histórico (MAINGUENEAU, 2008a). Embora a noção de discurso seja empregada com acepções distintas, entende-se por discurso uma dispersão de textos, cujo modo de 
inscrição histórica permite definir um espaço de questões enunciativas. Nas palavras do autor, "a instabilidade do campo da análise do discurso encontra correspondência na própria noção de discurso. Nenhuma obra de introdução esquece, aliás, de demorar-se neste ponto" (MAINGUENEAU, 2015, p. 23).

Falar em discurso é ativar um conjunto de saberes e acepções, que, compostos, de maneira difusa, estabelecem um objeto que se organiza por sequência textual, mas também além do texto; que é uma forma de ação e não apenas representação do mundo; que é interativo, contextualizado, regido por normas e composto por uma multiplicidade de outros discursos; e, principalmente, que é um objeto que constrói socialmente sentidos. Discurso, portanto, é um fenômeno humano por meio do qual a sociedade se constrói, se reconstrói e se manifesta. Contudo, por mais que essa definição pareça precisa e peremptória, a noção de discurso é fluida e diferente para cada corrente, para cada pesquisador, e as diversas noções coexistem sem se excluir.

Para a AD, pensar o discurso concerne articular diversos espaços que são tratados separadamente por outras ciências. É preciso considerar o confronto entre a língua, o léxico, o contexto social, o momento de gênese ou fala, as regras sob as quais aquele discurso está submetido. Ou seja, o analista vê-se numa posição de busca constante pelo equilíbrio, para não reduzir o discurso apenas a aspectos linguísticos, sociais ou psicológicos.

Trabalhar com AD é fazer escolhas desde o primeiro momento. $\mathrm{O}$ analista deve selecionar categorias que dependem dos objetivos da pesquisa, estabelecendo os níveis de análise do corpus. Selecionamos as categorias cena enunciativa, gênero de discurso e ethos, pois a concepção de gênero de discurso como prática social implica a noção de que ele é atravessado por outros discursos, cons- 
truído por agentes sociais no desenvolvimento de atividades com finalidades reconhecidas em espaços e cenas sociais específicas e o seu uso estabelece rotinas e modelos, que influenciam a prática social, ou seja, esses gêneros constituem a atividade e organização dos discursos dessas identidades sociais (BAZERMAN, 2005).

O discurso sempre é regido por normas, que podem estar explícitas e precisam ser compartilhadas. Maingueneau (2009) afirma que o discurso é reflexivo, ou seja, que, nos atos de fala, os enunciadores são atores, como em um teatro, e por isso fazem reflexões para retomar uma ação. Ao se falar, torna-se ator, portanto, deve-se estabelecer um padrão entre norma e realidade - a norma que se tem e a realidade em que se está. A AD apresenta uma maneira diferente de se olhar o discurso, uma vez que não é uma disciplina normativa, haja vista que para a $\mathrm{AD}$ interessa a noção de discurso como uma prática aberta de construção de sentido. $\mathrm{O}$ discurso é um espaço que emerge entre os elementos visuais e as palavras, e é nesse espaço que há entre o visual e as palavras onde se constitui o discurso.

Ainda nessa perspectiva, a relação com o discurso e a realidade se dá considerando que o discurso pertence ao mundo, mas, ao mesmo tempo em que lhe pertence, ele o constrói. Esse pertencimento e construção devem ser considerados, uma vez que as práticas discursivas constroem as realidades pela linguagem. $\mathrm{O}$ discurso é uma atividade que contribui para a construção do mundo, é por meio dele que nos relacionamos com a realidade, uma vez que ver o mundo também é construí-lo. "É por meio do discurso que se constrói a realidade social, e, portanto, todo empreendimento do conhecimento, inclusive os próprios estudos do discurso" (MAIGUENEAU, 2015, p. 179). Essa construção se dá por meio das situações sociais nas quais o discurso é produzido e pelas restrições discursivas e formais que advêm dessa ancoragem social dos dis- 
cursos e textos. Os enunciados relacionam-se com as especificidades de uma dada esfera da comunicação. Cada esfera na qual a linguagem é usada desenvolve seus tipos relativamente estáveis de enunciados, denominados "gêneros de discurso". O gênero de discurso, desse modo, tem uma incidência decisiva nas análises que buscam os efeitos de sentido possíveis para os enunciados.

Os discursos dos pontos de invocação, pertencentes ao gênero do discurso ponto de umbanda são responsáveis por criar uma atmosfera que propicie o desenrolar dos acontecimentos, é por meio deles que se invocam as entidades sobrenaturais que participarão do ritual; eles também são enunciados com a função de incentivar que as ações ritualísticas aconteçam nos momentos pré-determinados e alguns tipos desses discursos também são utilizados com a função de afastar os opositores.

\section{Os discursos da umbanda}

$\mathrm{Na}$ umbanda, "pontos cantados", também chamados de cantigas de umbanda ou cantigas rituais, é o nome que se dá a pequenas cantigas entoadas pelo atabaqueiro, pelos médiuns e pela assistência durante todo o ritual de culto às entidades e em outros encontros ou festividades, eles representam as forças e os valores daquela comunidade nas figuras construídas que, de acordo com a fé, se aproximam dos terreiros para os trabalhos, sejam de magia, de descarrego ou de desenvolvimento de médiuns. Segundo Carvalho (1997, p. 96), estes textos pertencem à esfera do sagrado e tratam de uma intrínseca rede poético-discursiva, sobre a qual muito ainda falta saber: 
Trata-se de pequenos cânticos, carregados de valor ritual, no momento em que foram gerados no contexto específico de uma tradição religiosa (...). Compostos predominantemente no modo lírico, esses fragmentos se vinculam a um rico universo mítico que não é necessariamente descrito por eles; pelo contrário, a mitopoética desses cantos existe para modificar e expandir esse mesmo universo de origem.

O autor acrescenta:

E na medida em que formam uma tradição eminentemente oral, não são "petrificados pela escrita", como é o caso das escrituras sagradas a que as reflexões da maioria dos filósofos se referem, mas são fixados (ou melhor, contidos) pelo verso, pelas melodias a eles associadas e pelas várias condições rituais a que se submete a sua criação (CARVALHO, 1997, p. 97).

Dos pontos de umbanda, por estarem inscritos na tradição oral que reconta constantemente os modos do fazer ritualístico e os mitos das entidades que o compõem, muitas vezes, são desconhecidos seus autores e suas datas de composição, bem como é possível encontrar muitas variações no código linguageiro de um mesmo ponto de umbanda a depender de cada terreiro. Entretanto, na música popular brasileira, podemos encontrar pontos de umbanda gravados por cantores como Clementina de Jesus, Maria Bethânia e Carlinhos Brown e, em diversos locais, existem concursos e festivais dedicados apenas a esse gênero (RIBEIRO, 2018). 
Para entoar as melodias dos pontos de umbanda, são formadas as curimbas nos terreiros, compostas de: atabaqueiros e cantores, sendo os primeiros os fundamentais, sem os quais não há toque no atabaque. É obrigação do atabaqueiro conhecer os diversos ritmos dos pontos e o momento certo de cantá-los. Ele deve saber o nome de todas as entidades espirituais que trabalham em seu terreiro, saber distinguir uma entidade de outra, e saber as saudações destinadas aos guias e orixás. A curimba é responsável pela preparação do ambiente, tornando-o propício e harmonizado com o plano espiritual.

Os pontos de umbanda são divididos em tipos e podem ser classificados, de acordo com sua função, da seguinte maneira: de abertura, cantados para indicar o início do ritual; de defumação, cantados durante o processo de defumação do local onde o ritual acontece; de bater cabeça, cumprimento em que os corpos se deitam no chão como gesto de humildade e reverência; de invocação, a chamada das entidades que serão incorporadas durante o ritual; de louvação, cantigas que enaltecem a linha das entidades que estão presentes e que são entoadas durante a maior parte do ritual; de descarrego, entoadas para ajudar quando há um momento de descarrego no ritual; de despedida, entoadas no momento da desincorporação; e de encerramento, cantadas no fim do ritual (ARRUDA, 2015).

Os discursos que serão analisados são enunciados com a finalidade de convocar, em uma espécie de chamamento, as entidades que serão incorporadas durante a gira. Os discursos de invocação em pontos de umbanda fornecem, de forma bastante similar aos que podem ser encontrados na literatura, uma fonte importante de análise para a identificação dos valores defendidos pela comunidade. As entidades invocadas por meio deles carregam traços marcantes que simbolizam o que se pode chamar de identidade cultural. 
O tom de uma invocação pode remontar à mera artificialidade de um recurso retórico propositalmente inserido para tornar a obra compatível com um pressuposto "modelo épico" como pode trazer o sentido da deprecação ou súplica, do comando, da cominação, imprecação ou ameaça, da apóstrofe ou interpelação direcionada a alguém, da evocação, que apela para a memória ou para o sobrenatural, da convocação, da exaltação, da submissão, da fragilidade etc. É necessário, na análise de uma invocação, reconhecer se o tom do chamamento tem significação dentro do dimensionamento do discurso. Muitas vezes, principalmente nos discursos contemporâneos, é visível a importância do chamamento no sentido de provocar, por exemplo, a aderência do invocado à intenção do texto, criando uma espécie de cumplicidade.

\section{Análise}

Nesta análise, em um primeiro momento, descrevemos separadamente as cenografias de cada discurso do corpus selecionado; em seguida, tratamos dos aspectos comuns a todos os discursos do corpus, como a sonoridade e o interdiscurso; na sequência, identificamos no gênero de discurso ponto de umbanda, suas especificidades e observamos o vínculo entre os enunciadores e seus co-enunciadores, parceiros da comunicação verbal e as regularidades enunciativas que revelam as maneiras pelas quais emerge o ethos discursivo como identidade cultural.

O discurso ponto de umbanda pode ser considerado um gênero híbrido, de caráter intersemiótico, pois é o resultado da conjugação de dois tipos de linguagens, a verbal e a musical (ritmo e melodia). Esse gênero exige três competências: a verbal, a musical e a lítero-musical (capacidade de articular as linguagens verbal e 
musical). Essa proposta vem ao encontro do que postula Maingueneau (2008b) quando este afirma que é necessário pensar a relação dos discursos abstratos (produção literária, filosófica, religiosa, pictórica, musical etc.) com suas condições de produção de modo menos trivial. Para isso, precisamos operar diretamente no nível das articulações fundamentais que possibilitam as unidades de interpretação.

O gênero ponto de umbanda, portanto, só pode ser compreendido quando consideradas todas as características que o compõem: um poema rimado e musicado, com ritmos fortes e bem marcados, melodias com propriedades hipnóticas, que é dedicado, em um ritual religioso, a exaltar figuras identitárias periféricas que compõem a sociedade brasileira ou deidades de matriz africana sincretizadas com os santos católicos ou elementos essenciais dos rituais de matriz africana. Nesse gênero emerge uma figura de enunciador que reivindica para si, na fusão com os elementos que louva, atributos valorativos dessa comunidade identitária como sapiência, força, destreza, habilidade secular e mística, felicidade, poder, fortuna etc., valores foram e são usados por diversas culturas como eufóricos e representados, em conjunção, com uma figura heroica.

\section{Discursos ponto de invocação de baiano na umbanda}

O primeiro discurso ponto de umbanda utilizado para a invocação de entidades da classe de espíritos baiano que analisamos é: 
Baiano bom, baiano bom

baiano bom, ele sabe trabalhar.

Baiano bom é o que sobe no coqueiro, pega o coco, bebe a água e bota o coco no lugar.

Esse discurso, com quatro enunciados, em terceira pessoa, tem como tema a descrição de um baiano considerado bom e seus atributos de força e destreza. Como é possível ver, por meio desse discurso, os baianos na umbanda compõem uma classe de espíritos associada a personagens nordestinos. Eles assumem várias facetas: desde o representante das camadas sociais que compõem as periferias das metrópoles, presente na enunciação pela valorização do saber trabalhar, até aquele que resiste às adversidades, que aparece no discurso pela busca por água de coco para beber.

As características relacionadas ao consumo da água de coco e da figura do nordestino são resgatadas na memória coletiva. Os baianos resgatam imagens ambíguas: tanto podem ser entidades tranquilas e irreverentes, que só "bebem água de coco", quanto podem aparecer como encrenqueiros e valentes, que realizam trabalhos. O baiano bom é aquele que "sabe trabalhar", termo que assume duplo sentido: pode ser compreendido como o trabalho secular, o labor; e também como o trabalho místico, a feitiçaria que, geralmente, outras entidades não se dispõem a realizar, tais como de ordem financeira ou ligados à intimidade, como adultério e desavenças. Ou seja, também por meio do código linguageiro, podemos encontrar os aspectos estereotípicos associados à classe de baianos, tais como a alegria, a festa, a briga, a malandragem, o sotaque baiano, a ginga do corpo, o xaxado, a postura ereta, porém descontraída. 
No discurso, o baiano bom convocado a participar da gira tem qualidades sobre-humanas. $\mathrm{O}$ enunciador apresenta sua capacidade de subir em um coqueiro, beber a água de um coco e colocar a fruta, magicamente, de volta em seu lugar na árvore, uma ação impossível pelas leis da física, mas que, em um contexto de misticismo demonstra a valoração da habilidade mágica. Essa cenografia da vida do cotidiano, um homem com sede e que sobe em um coqueiro para tomar água de coco, contribui para reforçar o traço da classe espiritual que se propõe louvar: os antepassados da Religião, pessoas comuns que foram pais de santo, ou seja, tinham algo de mágico em seu dia a dia e que retorna ao mundo dos vivos para trabalhar na umbanda. Souza (2001) defende que estão associados ao trabalho árduo, pobreza, analfabetismo, bairros periféricos e vida precária. A cenografia da vida simples do discurso acima representa essa associação, a busca por água de coco está associada ao trabalho.

O segundo discurso ponto de umbanda, característico para invocação das entidades da linha de baiano, pertence ao Baiano Mirongueiro, é o seguinte:

\section{Quando eu vim lá da Bahia, eu trouxe meu patuá. Baiano que tem mironga, baiano quer mirongar.} Bahia êê! Bahia êa!

O discurso é enunciado em primeira pessoa. Nele, vemos o enunciador contando de onde veio - da Bahia - e o que trouxe consigo - o objeto de proteção. Em um segundo momento, a cenografia se volta para uma acepção mais generalizada, fala-se do 
"baiano" enquanto classe espiritual, que tem "mironga"22 e quer "mirongar". Essa imagem que se constrói sobre o baiano guarda muitas relações com a próxima classe de pretos-velhos.

A cenografia registra a trajetória do Baiano Mirongueiro no âmbito místico. A Bahia de onde o sujeito vem é o local de origem da Religião, ou seja, o canto narra o expandir da Religião e por isso o "trazer do patuá", o elemento de proteção. Aqui, a cenografia contribui com as acepções de pertencimento; o sujeito discursivo, que veio da Bahia, representa o atual fiel também, é a ele que a assistência vai se adequar, com quem ela vai se identificar. A chegada do Baiano em outro lugar traz consigo a chegada da própria umban$\mathrm{da} /$ terreiro que o invoca. O ponto valida o pertencimento daquele grupo à umbanda. Alguns umbandistas afirmam que os baianos, em suas vidas anteriores, foram nordestinos pobres, brigões, pais-de-santo do candomblé da Bahia, macumbeiros; outros acreditam que eles foram negros ou mestiços de africanos com grande experiência; confundem-se com o baiano migrante do meio urbano paulista e o negro das cidades litorâneas da Bahia (Souza, 2001).

A vinda do baiano da Bahia com um patuá também conecta a classe espiritual de baiano com a de preto-velho, qualificando-o como "preto jovem", mas sobretudo por conta da sua condição de migrante (CONCONE, 2006, p. 19). A constituição da cenografia de alguém que conta a sua própria história, de alguém que tem algo para dizer do seu passado, como fazem os velhos, aproxima os coenunciadores. Essa cenografia cria efeitos de sentido de um ambiente de maior intimidade, como o que a assistência tem com o pai de santo do terreiro, que pede para fumar e beber, não repreende seus clientes ou agentes e assume um tom jocoso nas conversas com os consulentes.

22 "Palavra usada para dizer aquilo que ninguém sabe explicar" (CORACINI, 2008), ou realizar os segredos do ritual. 
De modo complementar, a imagem construída por meio do discurso da classe de baiano como um ethos discursivo, alguns autores, como Souza (2001) e Concone (2006) defendem que o histórico dessa entidade religiosa se correlaciona com os processos de mudança sofridos nas condições sócio-históricas e culturais de produção na sociedade brasileira em décadas recentes. Nesse sentido, deve-se destacar que o baiano é, sobretudo se comparado às entidades mais tradicionais e fundadoras do panteão umbandista, um "espírito novo" nos terreiros, e, segundo Souza (2001), surgido nas décadas de 1950 e 1960, quando ocorreu forte fluxo migratório de nordestinos para o estado de São Paulo, principalmente para compor o quadro urbano de trabalhadores não qualificados das construções civis e dos diferentes ramos da indústria automobilística então em grande expansão, especialmente devido à política de Juscelino Kubitschek na segunda metade da década de 1950 voltada à industrialização, à abertura da economia, ao capital estrangeiro e à construção de novas rodovias ligando as demais regiões ao Centro-Oeste e ao Sudeste do país.

Vemos que o que é narrado no discurso remete a um acontecimento histórico não apenas no plano dos vivos, mas também nos efeitos que essas condições de produção tiveram na própria composição do panteão de entidades da Religião. O crescimento da classe de espíritos de baiano em São Paulo acompanhou o crescimento da migração interna e o baiano, na verdade, é a imagem do migrante nordestino; uma síntese. Brumana e Martinez (1991, p. 257) aproximam-se dessa tese, acrescentando a hipótese de que "as entidades umbandistas não são criações ex nihilo do culto e sim a absorção de significantes preexistentes em diversos registros culturais".

O discurso nos permite dizer que o universo simbólico da umbanda foi elaborado de forma popular, espontânea, como re- 
flexo imediato da vivência de seus elaboradores, mesmo que não imediata, pois a umbanda se constitui em um processo de diálogo com mudanças sociais brasileiras, de modo que a análise de sua origem deve se referir dialeticamente às transformações sociais do país. Assim, as classes de espíritos no panteão umbandista são uma construção mítica destinada a conferir "sentido a um universo social sem significado, como tentativa de resolução coletiva dos problemas gerados pela vivência (...) anômica, dos grandes centros urbanos nas décadas iniciais do século" (NEGRÃO, 1996, p. 37). Os discursos de terreiros estão situados nos quadros sociais de referência em que se constrói a memória coletiva cujas estruturas são homólogas às encontradas na construção da memória, ambas operam segundo o processo de bricolagem, de recombinações de elementos extraídos da história vivida.

Os discursos dos pontos de umbanda do tipo de invocação da classe baiano nos permitem concordar com Prandi (1991), para quem a umbanda é um palco do Brasil e os discursos de terreiros, ao proporcionar uma imagem de si, também cuidam e reparam a imagem social de setores atingidos por discriminações e estigmas ferozes.

\section{Discursos ponto de invocação de preto-velho na umbanda}

O discurso de ponto de invocação dedicado às entidades da linha de pretos-velhos que analisamos é o seguinte: 


\begin{abstract}
Vovó tem sete saias, na última saia tem mironga
Vovó veio de Angola pra salvar filhos de umbanda

Com seu patuá, arruda e guiné, vovó veio de Angola pra salvar filhos de fé.
\end{abstract}

No discurso, podemos ver a figura de uma preta-velha no descer de uma serra segurando uma sacola, um amuleto de sorte e um trabalho místico. A designação dela é clara, ela vem de Angola, na África, remontando aos ancestrais africanos que vieram para o Brasil. Outro discurso de invocação semelhante diz o seguinte:

Lá vem preta-velha, descendo a serra com sua sacola, com seu patuá, com sua mandinga, ela vem de Angola. Eu quero ver vovó, eu quero ver, eu quero ver se filho de pemba tem querer.

O discurso de quatro enunciados se divide em dois momentos, o primeiro apresenta a entidade, o segundo em primeira pessoa, fala com a entidade em um tom de proximidade - ela é chamada de "vovó" - fala sobre os médiuns. O enunciador estabelece a força da entidade sobre os médiuns.

Esse é um discurso típico de terreiros de umbanda, que recebe algumas variações no código linguageiro a depender do terreiro onde é enunciado. A palavra "serra" em alguns lugares é substituída por "ladeira". Em outras versões, o segundo enunciado é substituído por "ela traz um rosário, ela traz uma guia, ela vem de Angola", alguns terreiros também enunciam esse discurso com a palavra "vovô", no masculino, para os pretos-velhos. Essas varia- 
ções ajudam a construir a figura da entidade e sua classe espiritual e são comuns nos discursos de terreiros como mostraremos nos demais discursos.

Os pontos para pretos-velhos apresentam cenografias semelhantes. Em ambos, as entidades, chamadas de "vovó" ou "vovô" têm ligação direta com Angola. Salvo pela ideia da serra no segundo, que mostra a diferença de altura entre o espaço habitado pelas entidades em relação ao espaço do mundo dos vivos, as entidades são apresentadas de forma idêntica, são seres que trazem, escondido - na última de sete saias ou em uma sacola - algum trabalho místico, uma mandinga ou uma mironga. Esse espaço-tempo, que une a vida dos homens e mulheres escravizados do passado ao ritual umbandista do presente contribui na perpetuação dos conceitos de valoração da velhice, e da sabedoria que se adquire com ela, que faz parte da cosmovisão de alguns povos africanos.

A classe de espíritos preto-velho é figura-chave na umbanda, sendo uma das mais antigas, mais encontradas nos terreiros e mais citadas em toda a literatura. No que diz respeito à sua antiguidade, é amplamente difundida entre umbandistas e pesquisadores a ideia de que os pretos-velhos foram, juntamente com os caboclos, os grandes precursores espirituais da umbanda, tendo sido estas as primeiras entidades do panteão a incorporarem e reivindicarem a fundação de uma nova Religião por meio da criação dos primeiros centros de umbanda, dos quais se tornaram os líderes espirituais e patronos (NEGRÃO, 1996). A ligação feita nos discursos que demonstra essa importância é com Angola, a figura dos pretos-velhos faz referência aos trazidos de África.

A apresentação da vestimenta da preta-velha com sete saias, bem como as referências à comunidade umbandista (filhos de fé e filho de pemba) nos permitem dizer que a classe de preto-velho 
é produto de um processo abrangente de sacralização e mitificação de personagens e fatos históricos, calcado na necessidade de atualização de memórias arraigadas no âmago das comunidades afro-brasileiras desde os primeiros tempos de suas afirmações culturais e identitárias. Memórias que guardam os momentos mais significativos e coerentes das vidas humanas; vozes que ecoam na história e em vívidas experiências pessoais em que singular e coletivo emergem e se encontram, e a experiência de cada um pode mover-se através das lembranças e vidas dos outros, ganhando alcance comunitário e expressando situações comuns ao grupo.

Os pretos-velhos, enquanto representação da figura de homens e mulheres negros escravizados tal como fixada na memória coletiva, são entidades que rememoram à experiência histórica da escravidão, consubstanciada na forma de espíritos de escravizados, ou ancestrais de origem africana e afro-brasileira, e de suas respectivas histórias de vida, trajetórias e legados existenciais; homens e mulheres negros que, antes de morrerem e retornarem sacralizados para intervirem no mundo de seus descendentes vivos, efetivamente trabalharam, suaram, sofreram, sangraram, rezaram, lutaram, curaram, aprenderam, se revoltaram, enfeitiçaram, sonharam, viveram.

\section{Discursos ponto de invocação de caboclo na umbanda}

Ao chegarem a terras brasileiras, os povos da cultura banto passaram a cultuar os espíritos ancestrais dos indígenas, tidos como primeiros habitantes dos espaços onde eles se encontravam. Segundo Prandi (1997), tal inclusão na prática religiosa banto, de adoção dos ancestrais indígenas brasileiros, trouxe uma enorme 
diversidade de entidades a ser cultuada nos terreiros, colocando a classe de espíritos "caboclo" em posição de destaque. Caboclas e caboclos são conhecidos não só na umbanda. Entre as figuras sagradas presentes nas várias religiões afro-brasileiras, eles formam uma linha de entidades espirituais bastante recorrente. Seus fiéis relacionam-se com os espíritos caboclos durante os rituais e fora deles, nas suas vidas cotidianas. Pode-se dizer que suas manifestações satisfazem anseios e dão sentidos a vivências dos praticantes contemporâneos desses cultos, pois possuem significativo espaço e força entre seus adeptos.

Um dos discursos enunciados para invocação de caboclo é o que segue:
Atravessei o mar a nado,
encima de dois barris.
Eu vinha ver a Juremeira
e os caboclos do Brasil.

O discurso, em primeira pessoa, mostra um enunciador que diz ter atravessando o mar por cima de dois barris em uma evidente demonstração de força, vindo ver a Jurema ${ }^{23}$ e os outros caboclos do Brasil.

É bastante comum que a palavra "barris" seja enunciada no singular para marcar a rima com "Brasil". Esse discurso, também de quatro enunciados, apresenta variações no terceiro enunciado que pode ser composto da seguinte maneira "foi só pra ver a Juremeira", ou "foi para ver a Juremeira".

23 As complexidades acerca das acepções da palavra "jurema” são discutidas no trabalho de Bairrão (2003). Jurema é uma árvore, uma bebida, uma cerimônia religiosa, uma entidade espiritual, um local de culto, uma linha de entidades, uma cidade, uma mata, entre outros. 
Outro discurso comum de invocação de caboclo é o que segue:

\author{
O galo cantou lá na Jurema \\ foi pra chamar os caboclos dessa tenda. \\ Pisa caboclo, quero ver pisar. \\ Pisa caboclo, eles vêm pra trabalhar.
}

Nesse discurso de quatro enunciados, o enunciador diz que há um galo na mata que cantou chamando as entidades. Esse enunciador diz "pisa caboclo", que significa que os caboclos já podem se fazer presentes na gira, e afirma que a entrada das entidades está relacionada ao trabalho espiritual que será feito no ritual.

Os discursos ponto de invocação de caboclo constituem cenografias que destoam das até aqui descritas. Eles não fazem referência ao universo do negro, mas do índio. O primeiro ponto estabelece a cena de um índio forte que atravessa o mar para vir cultuar o ambiente da mata, ou a árvore juremeira, e os caboclos do Brasil. Não é evidente, pelo texto do ponto, que o enunciador é também pertencente à classe espiritual de caboclo, contudo, a força sobrenatural demonstrada na travessia de um mar a nado sobre apenas dois barris, leva-nos a considerar que, mesmo que não fosse parte, o ethos construído é de uma entidade.

Já o segundo ponto de chamada de caboclo constrói a cenografia de índios em uma mata convocados pelo cantar de um galo, um canto mágico que avisa às entidades que é hora de ir trabalhar no mundo dos vivos. O ponto também fala do próprio ritual que está acontecendo, o enunciador dirige-se diretamente a entidade o convocando a aparecer - a pisar no terreiro. 
A classe de espíritos caboclo também é bastante conhecida na comunidade acadêmica. Os espíritos caboclos foram estudados por diversos autores, que os associam a uma imagem do indígena brasileiro. Carneiro (1964) afirmou que em rituais em que eles aparecem, podem-se observar acessórios como penas, cocares, tacapes, arcos e flechas, além de um linguajar que traz alguns termos supostamente do tupi-guarani. De acordo com Santos (1995), os caboclos podem ser vistos como "molde de uma representação que dá conta do índio como legítimo dono da terra" (p. 12). Negrão (1996) defendeu que, para os fiéis das religiões afro-brasileiras, caboclo é índio na condição de espíritos de luz após sua morte. Seriam espíritos dos antepassados indígenas brasileiros (ORTIZ, 1999). Silva (2005) afirmou que eles são os representantes dos índios que viviam no Brasil antes da chegada de brancos e negros.

Apesar de estes espíritos serem cultuados em diversas partes do país, em várias religiões de influência africana, o contexto umbandista paulista é tido como rico em material simbólico porque "concretiza-se em tradições vivas, psiquicamente intervenientes em dinâmicas pessoais e sociais" (Bairrão, 2003, p. 285).

\section{Discursos ponto de invocação de exu na umbanda}

Os discursos pontos de invocação de exu e pombagira que compõem o corpus dessa análise são:

Não era meia-noite quando o malvado chegou vestindo capa preta dizendo que era doutor, mas ele é exu dizendo que era doutor. Ele é exu dizendo que era doutor. 
Deu meia-noite, a lua se escondeu.

Lá na encruzilhada dando a sua gargalhada Pombagira apareceu. É laroiê! É mojubá! Ela é odara dando a sua gargalhada quem tem fé em Pombagira é só pedir que ela dá.

Nos discursos, percebemos que a invocação dessas entidades não convoca uma longa viagem ou a falta de pertencimento ao plano dos vivos, o que os diferencia dos discursos vistos até agora. Em terceira pessoa, eles trazem informações sobre a chegada das entidades, no primeiro, exu chega vestindo uma capa preta e se dizendo doutor, enquanto no segundo, o exu aparece em uma encruzilhada rindo. Os discursos também trazem aspectos da personalidade dos exus, enquanto o primeiro é chamado de malvado, o segundo é tido como odara, palavra iorubá que significa excelente. Ambas podem ser encontradas com variações em diferentes terreiros de umbanda. O nome "Pombagira" pode ser trocado pelo nome de qualquer outra entidade da classe de exu, por exemplo.

O Exu Doutor aparece próximo à meia-noite, vestindo uma capa preta, ou seja, é o ambiente oposto ao do hospital e do jaleco branco, ele está relacionado à figura do advogado. Vemos a capa-preta dos meirinhos e das becas nas cortes sendo subvertida pela capa-preta do Exu que despacha nas encruzilhadas. A cenografia que remonta ao imaginário do Mal, é corroborada pelo termo "malvado" e pela oposição estabelecida pela palavra "mas". Já a Pombagira aparece em uma encruzilhada, o espaço externo, da 
rua, em plena madrugada de uma noite tão escura que até mesmo a lua se esconde, mas ela parece sorrindo, gargalhando, para dar qualquer coisa que lhe for solicitado por quem tem fé. Em ambas as cenografias há um jogo de dualidades, o bem e o mal da moral cristã flertam entre si nessas canções.

A umbanda, diferente do imaginário popular, não associa a figura das entidades que pertencem à classe espiritual de exu a uma instância metafísica do mal. Elas são identificadas como zeladores de bens e prazeres pessoais e imediatos que são proibidos em função de interesses alheios aos do indivíduo, embora habitualmente legitimados em função do "seu" bem. Por vezes os interesses de distintas pessoas ou grupos são antagônicos e é neste caso que o bem alheio pode ser sentido como um mal pessoal, nunca um Mal absoluto.

Segundo Prandi (1996), é o papel de oposição a essa expropriação de bens pessoais, afetivos e de todo o tipo, que o exu cumpre na umbanda. A sua assimilação ao diabo é recusada por muitos umbandistas que tentam disciplinar a espontaneidade do imaginário. Entretanto, a umbanda se vale da figura constituída do diabo na caracterização dos traços dessas entidades.

\section{O ethos discursivo como identidade cultural nos discursos pontos de umbanda}

Os discursos apresentados compõem um hinário muito mais vasto com outros tipos de pontos de umbanda como já foi dito, contudo compreendemos que são estes suficientes para a apreensão das regularidades enunciativas do gênero de discurso. Eles são, como define Andrade (1963), um tipo de música fortemente rit- 
mado; possuem caráter incisivo à dança, coreográfico, devido às repetições, um forte valor hipnótico. Eles são enunciados com a finalidade de convocar, em uma espécie de chamamento, as entidades que serão incorporadas durante a gira e é por meio deles que as entidades são celebradas e convocadas a estarem presentes. As entidades assumem papel de co-enunciadores, quando a elas se dirigem dos discursos, por exemplo no enunciado "Pisa, caboclo", e de enunciadores, quando o "eu" do discurso diz respeito a elas, por exemplo no enunciado "Atravessei o mar a nado". Essa alternância de papéis colabora com o efeito de sentido de chegada das entidades e de transe e incorporação, pois ao enunciarem os discursos, os fiéis ouvem tanto a si mesmos chamando a entidade quanto à resposta da entidade.

Os discursos ponto de invocação das entidades apresentam as características que compõem as identidades do imaginário da umbanda: o idoso sábio e religioso (Com seu patuá, arruda e guiné,/ vovó veio de Angola pra salvar filhos de fé), o índio forte (Atravessei o mar a nado/ encima de dois barris), o malandro mentiroso (Ele é exu dizendo que era doutor), a mulher da rua risonha (com a sua gargalhada pombogira apareceu) etc. Essas identidades carregam as construções de valor sócio-históricas da constituição e manutenção da própria Religião. Ao evidenciar cada uma dessas figuras, que compõem ou compuseram a sociedade brasileira como classes de espíritos, os discursos de terreiros mostram seus posicionamentos, suas formações discursivas.

Podemos identificar as relações que os discursos de terreiros estabelecem como outros campos discursivos nos pontos de umbanda de invocação. O posicionamento sobre a velhice, por exemplo, aparece nos pontos de invocação de pretos-velhos, para a umbanda a velhice cria uma figura de grande conhecimento, que deve ser respeitada acima das vontades dos mais jovens (eu quero 
ver vovó, se filho de umbanda tem querer). Já o posicionamento acerca das identidades dos trabalhadores braçais aparece nos pontos de invocação de marinheiro e de baiano, neles a destreza e a dedicação ao trabalho, seja ele secular ou religioso, são qualidades dignas de louvor (baiano bom sabe trabalhar / quem te ensinou a navegar).

Os discursos não devem ser desvinculados de suas condições sócio-históricas de produção. Os discursos de terreiros ponto de umbanda são enunciados durante um ritual religioso, eles enaltecem e elevam as figuras que criam a um status de seres a serem adorados, desse modo as FD dos discursos pontos de umbanda estão em um embate claro com frases feitas de conhecimento popular que denigrem de maneira xenofóbica os nordestinos, ou que atribuem aos trabalhadores braçais, como os marinheiros, características de ignorância e preguiça.

O discurso acerca do índio nos discursos pontos de invocação na umbanda está sempre ligado à mata. $\mathrm{O}$ caboclo é uma figura distante da vida urbana, ele está na mata quando ou em algum lugar distanciado pelo mar. Essa separação pode ser tida como um posicionamento. A ideia de preservação das matas por meio desse guardião indígena é frequente na Religião e pode ser vista pela pluralidade de sentidos construída sobre a palavra "Jurema". Jurema, como afirma Bairrão (2003), é sinônimo de mata, floresta, lugar distante onde vivem os caboclos, mas também é sinônimo do espaço celeste que habitam todas as entidades, Aruanda.

Sobre as figuras urbanas da rua, os malandros, exus e pombagiras, os discursos de terreiros se posicionam em valorização da liberdade, uma espécie de liberdade que resiste à moralização cristã, como é possível ver na figura da mulher gargalhando na encruzilhada no meio da noite. Essas figuras são chamadas em ambientes 
de falta de luz, com adjetivos como "malvado", e mostrando ações tidas como reprováveis por um olhar moralizante, como mentir - dizer que se é doutor - ou mulheres gargalhando no meio da rua à meia-noite. Se colocarmos essas ações descritas nos pontos em uma chave valorativa de polaridade bem e mal, não estaremos sendo justos com a umbanda. O posicionamento desses discursos está em favor da liberdade de expressão, da igualdade de gênero, da resistência a uma moral paralisante.

É porque os discursos de terreiros dialogam e combatem outros discursos que confirmamos a hipótese do primado do interdiscurso defendida por Maingueneau em sua abordagem, pois um discurso não existe sozinho, mas dialogando com outros, por exemplo, a valorização do índio da mata (o galo cantou lá na Jure$\mathrm{ma} /$ para chamar os caboclos dessa tenda) retoma o lugar do índio como herói brasileiro da literatura brasileira do início do século XX (vide que o impulso todo do Romantismo e do "Il Guarany" é retomado por Vargas, bem no momento em que se consolidam as umbandas no Brasil), e Gonçalves Dias, na questão do "meu canto de morte, guerreiros, ouvi!" do I-Juca Pirama. Definido como um conjunto de discursos que mantém entre si uma relação discursiva, o interdiscurso está relacionado à memória coletiva onde acontece o funcionamento do discurso em que os sujeitos estão inscritos e se posicionam.

Esses posicionamentos são possíveis dentro dos pontos de umbanda por causa de sua cena de enunciação. O quadro cênico, espaço de estabilidade no qual o enunciado ganha sentido (MAINGUENEAU, 2008a, p. 115-116) é o do discurso religioso, em uma situação ritual de invocação de entidades com traços divinizados. Os enunciadores e co-enunciadores nesse discurso religioso são os fiéis - a assistência com os componentes da curimba -, os médiuns e as próprias entidades, eles compartilham de um universo de sen- 
tidos religiosos e culturais criados ao longo dos anos de formação da fé, e que é reiterado e reformulado a cada enunciação.

É por meio da enunciação, ato pelo qual o sujeito negocia o sentido, que se produz o enunciado, exigindo do enunciador as competências para que o co-enunciador aceite como verdade ou mentira, realidade ou ficção, aquilo que está em jogo. É nela que os diversos indivíduos se congregam em uma só comunidade, nas estruturas discursivas assumidas pelos sujeitos da enunciação que designam uma pessoa que se enuncia em um dado espaço, o terreiro, e em um determinado tempo, a gira.

Todas as cenas construídas nos discursos propostos são cenas em que uma entidade chega ao terreiro de umbanda vinda de algum outro lugar, geralmente, o espaço místico onde habita, é essa característica que determina a qual tipo de ponto de umbanda o canto pertence. Mais ainda, é preciso lembrar que na cena enunciativa em que esse discurso é proferido, a assistência também performa, atuando como um vaticinador, um místico que tem poder de invocar, misticamente até, aquelas figuras.

A cenografia remete a invocação de uma entidade que passa do seu lugar no plano místico para dentro do terreiro, ou, mais especificamente, para o corpo mediúnico, e é construída com base em cenas validadas, isto é, cenas de fala "já instaladas na memória coletiva, seja a título de modelos que se rejeitam ou de modelos que se valorizam" (MAINGUENEAU, 2001, p.92). E uma cena validada "não se caracteriza propriamente como discurso, mas como um estereótipo [...] disponível para reinvestimentos em outros textos" (MAINGUENEAU, 2001, p. 92), como o índio na mata; o malandro na rua; o africano em Angola; o baiano na Bahia, etc. Por isso, é nela que emerge o ethos, que, como dissemos, não é puramente linguístico, uma vez que a imagem de si é construída no e 
pelo discurso. Os sujeitos enunciadores desses pontos conferem a si próprios e ao enunciatário status de legitimidade (MAINGUENEAU, 2016). O ethos discursivo é mais que uma postura que demonstra seu pertencimento a determinado grupo dominante, mais que uma manifestação linguística, ou autorretrato de bom caráter, a imagem de si construída no e pelo discurso com vistas a influenciar opiniões e atitudes.

O ethos construído nesses discursos apresenta o tom, vinculado a um caráter que corresponde a características psicológicas atribuídas pelos co-enunciadores da enunciação à figura do enunciador e a uma corporalidade. Essas características na verdade são estereótipos que circulam na sociedade. Esses discursos revelam a junção das entidades com o valor do pertencimento, afinal, todos vão trabalhar na umbanda, mostrando uma narrativa mínima de liquidação dessa junção.

O ethos é constituído pelo que enuncia, em cada um dos pontos de umbanda o enunciador se posiciona como alguém que valoriza as figuras periféricas da sociedade brasileira: negros nordestinos, velhos, pobres, índios, malandros, prostitutas etc. Os tipos estereotipados que são criados nos cantos com os quais o enunciador se identifica vão na contracorrente do valor da moralidade cristã europeizada e os valores atribuídos a eles entram, muitas vezes, em conflito com os discursos da memória coletiva.

O discursivo é construído pelo o que se fala e por como se falar. Nos pontos de umbanda, é comum que o "eu" que enuncia o discurso possa ser identificado como "entidade", e, em outros momentos, como "fiel", esse jogo do sujeito da enunciação na mudança dos papéis não indica um diálogo entre as instâncias da enunciação, mas constrói na própria materialidade linguística o processo místico da incorporação. Dos pontos selecionados, os que melhor mostram essa estratégia são o ponto de marinheiro e o ponto de baiano 
em que, ora o "eu" pode ser identificado como entidade, ora não pode. Essa unidade pode ser vista, no plano da expressão, pelos ritmos das batidas simples e pontuais, que são fáceis de marcar e, por esse motivo, são envolventes - os participantes dos rituais são contagiados por eles.

Nos discursos analisados, vê-se que a identidade cultural do umbandista é criada a partir de estratégias enunciativas baseadas em associações com elementos de valor: ter uma conexão direta com o passado mítico (ela vem de Angola), ter uma conexão com a mata mística (o galo cantou lá na Jurema); carregar elementos de valor (eu trouxe meu patuá; na última saia tem mironga; com seu patuá, com sua mandinga, ela vem de Angola); e associações com performance: ter habilidades sobrenaturais (Atravessei o mar a nado; pega o coco, bebe a água e bota o coco no lugar); ter conhecimentos advindos de vivência aventureira (quem te ensinou a navegar,/ foi o tombo do navio/ ou foi o balanço do mar); ter poder sanar qualquer desejo (é só pedir que ela dá). Essa identidade é construída recuperando parte dos estereótipos de representação de grupos culturais, um amálgama contemporâneo que faz emergir a ideia de que o umbandista é composto por todas as minorias que resistem ao avanço do branco, e representante de uma identidade coletiva fragmentada.

A identidade cultural é aquela que preenche os espaços de mediação entre os mundos interior, mais pessoal, e exterior, mais público. O processo de construção dessa identidade cultural do umbandista demonstra a projeção do mundo particular nas ações de resistência, nos desejos de liberdade da moral cristã, mas também na internalização de valores comumente defendidos como a força, a ancestralidade, a glória imaterial. É nessa relação em que esse ethos, que só pode ser identificado quando reunimos as regularidades do gênero, pode ser compreendido. 
Ao defender que as figuras periféricas da sociedade brasileira, cada uma a seu modo e de acordo com seu estereótipo, podem atuar com traços heroicizados, todas elas trabalham na umbanda para salvar ou melhorar a vida da assistência, e fundir por meio das estratégias enunciativas descritas acima essas figuras com o ethos dos cantos, os discursos de terreiros se mostram como um discurso de resistência de grupos identitários que foram e são subjugados na nossa sociedade.

\section{Considerações finais}

Este capítulo examinou os modos de organização do gênero de discurso ponto de umbanda e a representação da identidade cultural nas instâncias enunciativas que organizam esses discursos, a fim de ressaltar suas especificidades e as relações que estabelecem entre si no processo de construção da identidade heroica. E, por saber que, nesses discursos, letra e música se confinam, em função do alcance de nossa pesquisa, nos concentramos nas marcas linguístico-discursivas que os materializam em textos, sem desconsiderar as dimensões sígnicas que lhes são inerentes do universo musical.

$\mathrm{Na}$ análise, identificamos os modos de organização do gênero de discurso ponto de umbanda e de inscrição dos sujeitos na cenografia, bem como verificamos o estatuto genérico dos discursos selecionados, suas especificidades e a forma como se constitui o ethos discursivo, tomado na construção da identidade cultural; e enumeramos o conjunto de estratégias, operações e parâmetros que servem de controle das tensões e dos contrastes decorrentes das formações discursivas em embate nos discursos selecionados. 
Debruçamo-nos sobre as questões que envolvem os discursos do ponto de umbanda para entender algumas das identidades que compõem a sociedade brasileira e os mecanismos que constroem, pelo discurso, os valores que ela defende. Embora cada um desses discursos possua características próprias, eles são usados, de igual modo, para invocar e reafirmar o valor social ou conferir poder, encorajar e apresentar uma entidade espiritual que representa uma identidade cultural.

Observamos que o gênero ponto de umbanda só pode ser compreendido quando consideradas todas as características que o compõem: um poema rimado e musicado, com ritmos fortes e bem marcados, melodias com propriedades hipnóticas, que é dedicado, em um ritual religioso, a exaltar figuras identitárias periféricas que compõem a sociedade brasileira ou deidades de matriz africana sincretizadas com os santos católicos ou elementos essenciais dos rituais de matriz africana. Nesse gênero emerge uma figura de enunciador que reivindica para si, na fusão com os elementos que louva, atributos valorativos dessa comunidade identitária como sapiência, força, destreza, habilidade secular e mística, felicidade, poder, fortuna etc., valores foram e são usados por diversas culturas como eufóricos e representados, fundamentando a identidade cultural.

Nos discursos em questão, vê-se que as identidades culturais que fazem parte do coletivo umbandista são criadas a partir de estratégias enunciativas baseadas em associações com elementos de valor: ter uma conexão direta com o passado mítico (vir de Angola), ter uma conexão com a mata mística (vir da Jurema); carregar elementos de valor (patuá, mandinga, mironga); e associações com performance: ter habilidades sobrenaturais (atravessar o mar a nado, devolver um coco em um coqueiro); ter conhecimentos advindos de vivência aventureira (aprender a navegar com o tom- 
bo do navio); ter poder para sanar qualquer desejo (é só pedir que ela dá).

Buscamos explorar uma inversão de perspectiva, trazendo os discursos daqueles que são tidos, muitas vezes, como público da atuação social, como a plateia que recebe e valida os discursos institucionalizados. Mostramos que a multidão de expectadores que compõe os bancos dos terreiros tem um discurso próprio que é fundamental para que os respectivos rituais aconteçam. Nossa abordagem amplia o diálogo e assinala quão importante é olharmos para nossas práticas sociais na tentativa de compreender a sociedade em que vivemos e, assim, construir um mundo melhor.

Em resumo, o gênero de discurso analisado trata de discursos padronizados que podem ser encontrados nas práticas da sociedade sob diversas formas e que tornam o pertencimento um valor eufórico, por meio de representações de identidades culturais em formas heroicizadas, associando-o às ideias de sapiência, força, misticismo, habilidade, poder, liberdade e, acima dessas, no caso da umbanda, resistência.

\section{Referências}

ANDRADE, Mário de. Música de feitiçaria no Brasil. São Paulo: Martins, 1963.

BAIRRÃO, José Francisco Miguel Henriques. Raízes da Jurema. Psicol. USP, São Paulo, v. 14, n. 1, p. 157-184, 2003. BAZERMAN, Charles. Gêneros textuais, tipificação e interação. São Paulo: Cortez, 2005.

BRUMANA, Fernando Giobelina; GONZALEZ MARTINEZ, Elda. Marginália sagrada. Campinas: Ed. Unicamp, 1991. 
CARNEIRO, Edison. Ladinos e crioulos. Rio de Janeiro: Civilização Brasileira, 1964.

CONCONE, Maria Helena Villas Boas. O ator e seu personagem [Versão eletrônica]. Revista Nures, 2(4), 1-34. Disponível em: <http://www.pucsp.br/nures/revista4/nures4_mariahelena.pdf $>$. Acesso em: 18 out. 2018.

CORACINI, Erika Regina Faria. Jongo e teatro: leituras performáticas da festa. 2008. Dissertação (Mestrado em Teoria e Prática do Teatro) - ECA. São Paulo, 2008.

MAINGUENEAU, Dominique. Termos-chaves da Análise do Discurso. Belo Horizonte: UFMG, 2000.

. Análise de textos de comunicação. 6. ed. ampl. São Paulo: Cortez, 2001.

. Cenas da enunciação. São Paulo: Parábola, 2008a. . Gênese do discurso. São Paulo: Parábola, 2008b.

. Discurso literário. São Paulo: Contexto, 2009.

. Doze conceitos em análise do discurso. São Paulo:

Parábola, 2010.

. Discurso e análise do discurso. São Paulo: Parábola, 2015.

. Retorno crítico sobre o ethos. In: BARONA, R. L.; MESTI, P. C.; CARREON, R. de O. (org.). Análise do discurso: entorno da problemática do ethos, do político e de discursos constituintes. Campinas, SP: Pontes Editores, 2016.

NEGRÃO, Lisias Nogueira. Entre a cruz e a encruzilhada. São Paulo: Edusp, 1996.

ORTIZ, Renato. A morte branca do feiticeiro negro: umbanda e sociedade brasileira. São Paulo: Brasiliense, 1999.

PIERUCCI, Antônio Flávio. Bye bye, Brasil: o declínio das religiões tradicionais no Censo 2000. Estud. av. [online]. 2004, vol.18, n.52, p.17-28. Disponível em: $<$ http://www.scielo.br/scielo.php?script=sci_arttext\&pi$\mathrm{d}=\mathrm{S} 0103-40142004000300003 \& \operatorname{lng}=\mathrm{en} \& \mathrm{nrm}=\mathrm{iso}>$. Acesso em: 04 set. 2019 
PRANDI, Reginaldo. Os candomblés de São Paulo: a velha magia na metrópole nova. São Paulo: HUCITEC: Editora da Universidade de São Paulo, 1991.

- Pombagira e as faces inconfessas do Brasil. In: . Herdeiras do Axé. São Paulo, Hucitec, 1996, Capítulo IV, p. 139-164.

. As religiões negras do Brasil - Para uma sociologia dos cultos afro-brasileiros. Revista USP, (28), 1997, p. 64-83. RIBEIRO, Geraldo. Rio tem circuito pouco conhecido de cantigas de umbanda e maior encontro de curimbas do Brasil. Extra digital, 11 jun. 2018. Disponível em: <https://extra. globo.com/noticias/rio/rio-tem-circuito-pouco-conhecido-de-cantigas-de-umbanda-maior-encontro-de-curimbas-do-brasil-22751931.html >. Acesso em: 14 out. 2018.

SANTOS, Jocélio Teles dos. O dono da terra. Salvador: Sarah Letras, 1995.

SILVA, Vagner Gonçalves da. Candomblé e umbanda. Caminhos da devoção brasileira. São Paulo: Selo Negro, 2005. SOUZA, Mônica Dias de. Escrava Anastácia: construção de um símbolo e a re-construção da memória e identidade dos membros da Irmandade do Rosário e São Benedito dos Homens Pretos. Dissertação de Mestrado. Instituto de Ciências Humanas e Filosofia, Universidade Federal Fluminense, Niterói, RJ. 2001.

. Pretos-velhos: oráculos, crença e magia entre os cariocas. Tese de Doutorado. Instituto de Filosofia e Ciências Sociais, Universidade Federal do Rio de Janeiro, Rio de Janeiro, RJ. 2006. 